\title{
Mothers' Knowledge And Attitude Towards Infant And Young Child Feeding Practices In Shashemene City, Oromia- Ethiopia 2020
}

Junayde Abdurahmen Ahmed ( $\sim$ juneabdu@gmail.com )

Madda Walabu University Shashemene Campus https://orcid.org/0000-0002-7783-7883

Kebede Kumsa

Madda Walabu University Shashemene Campus

Kelil Hussen

Madda Walabu University Shashemene Campus

Aster Yalew

Madda Walabu University Shashemene Campus

\section{Research}

Keywords: Mother's knowledge, Attitude, complementary feeding practice and Oromia.

Posted Date: November 12th, 2021

DOI: https://doi.org/10.21203/rs.3.rs-983355/v1

License: (c) (i) This work is licensed under a Creative Commons Attribution 4.0 International License. Read Full License 


\section{Abstract}

The scheme youngsters are fed has a huge impact on their development. Poor breastfeeding and infant feeding practices have a negative impact on children's health and nutritional status.

Purpose: The study's aim was to analyze mothers' knowledge, attitudes, and practices (KAP) regarding supplemental feeding of children aged 6-23 months in Shashamene City, Oromia Ethiopia.

Methods : A community based cross-sectional study was conducted from January 1 -january 28 using a two-stage sampling procès to chose 536 women with children aged 6 to 23 months for the study. The Statistical Package for the Social Sciences (SPSS) software were used to analyze the data. The characteristics related with complementary feeding (CF) practice were identified using logistic regression, and statistical significance was determined at $p$-value of less than 0.05 .

Results: This study found that complementary food was first introduced at the age of 6 months, 353 (68.4\%) and 167 (32.1\%) at greater and Less than 6 months age with bottle feeding (AOR: 0.27, $95 \% \mathrm{Cl}$ : $(0.13,0.55)$ ). Sources of information about the advantages of breast milk (AOR:4.3495 \% $\mathrm{Cl}(1.96,9.60)$ ), minimum dietary diversity (AOR:2.21,95\% Cl(1.01,4.85)), knowledge about iron-rich foods (AOR:0.029,95 $\% \mathrm{Cl}(0.04,0.21)$ ), knowledge about iodine-rich foods (AOR:0.022,95\% $\mathrm{Cl}(0.03,0.16)$ ) were discovered to be independent predictors of mother's knowledge on appropriate infant feeding

Conclusion: Mothers' knowledge about the timing of CF practices is low in this study. Botte feeding, sources of information about the benefits of breast Milk, a minimum dietary diversity, knowledge about infant and young child feeding were the indépendant factors that significantly associated with mother's knowledge of appropriate infant and Young Child feeding practices.

\section{Background}

Children are particularly vulnerable to malnutrition in developing countries due to inadequate dietary intakes, a lack of appropriate care, and inequitable food distribution within households $[1,2]$. Appropriate feeding practices are critical for improving nutritional status and ensuring child survival. Inadequate feeding practices are often linked to $2 / 3^{\text {rd }}$ of the 10.9 million deaths among children under the age of five worldwide [3,4]. CF is the gradual introduction of solid and semisolid foods into an infant's diet when breast milk alone is insufficient to meet the infant's nutritional needs. The age range for CF is considered to be 6 to 24 months, despite the fact that breastfeeding may continue for up to 2 years [3].

To monitor and guide infant and young child feeding practices, the World Health Organization (WHO) developed eight core and seven optional indicators $[5,6]$. Ethiopia, one of the Sub-Saharan African countries with a high level of malnutrition, launched a national strategy for infant and young child feeding in 2004 to improve children's nutritional status [7]. The WHO recommends using a combination of indicators to assess the level of appropriate $\mathrm{CF}$, but most studies on complementary practices have used a single indicator with a narrow age range, failing to adequately quantify the level and determinants of 
appropriate complementary feeding practices (ACFP) [5,6]. Mothers' knowledge of appropriate CF has a greater impact on children's nutritional status than a lack of food; identifying gaps in feeding practices aids in the planning of interventions to improve feeding practices $[7,8]$.

According to a study conducted in Nagele Arise, the rate of appropriate CF was $9.5 \%$. [9]. Infant feeding practices are changing over time and place as a result of modernization, changing lifestyles, and increased urbanization. Scarcity of information on appropriate CF on Infant Young Child Feeding (IYCF) in Ethiopia, calls for a study setting to explain the level of appropriate CF about IYCF and associated factors. Besides this, study serves as a baseline for future research. Yet, it had never been assessed in Shashemene city as a result; the study was designed to analyze mothers' KAP on Infant Young Child Feeding (IYCF) in study area. The findings will aid in the promotion of appropriate CF.

\section{Methods}

\section{Area and subjects}

The study was conducted in Shashemene city from January 1-28 in 2020. Shashemene is the most densely populated town with diversified ethnic groups of the population. It is located $250 \mathrm{~km}$ from Finfine, the capital city of Ethiopia. Climatically, Shashemene city falls into subtropical climatic zones: The Population of Shashemene city is estimated to be 272193: 50.4\% male and $49.6 \%$ are female in 2019 Children aged 6-23 months of age constituted $4.8 \%$ of the population i .e.13065 as to Shashemene health office report. Regarding Study Design and Population, a community-based cross-sectional study was conducted in Shashemene city, Oromia, Ethiopia. All mothers with children aged 6-23 months who lived in Shashemene city by 2020 were considered the source population, whereas mothers with children aged 6-23 months who lived in selected households during the study period and lived in the study area for more than 6 months were considered as the study population.

\section{Sample Size determination}

The sample size was determined by a single population proportion formula taking the proportion of ACFP $11.4 \%$ from the previous study [10]. The following assumptions were used; margin of error $=4 \%, Z a=1.96$, and design effect $=2.243$ samples were obtained with consideration of $10 \%$ contingency to nonresponders a total of 536 mothers sampled.

$$
\left.n_{o}=\frac{z \alpha / 2^{2} p(1-p)}{d^{2}} \quad m\right) \mathrm{n}=\frac{(1.96)^{2} * 0.114(1-0.114)}{(0.04)^{2}} \quad=243,243 * 2+48=\underline{\mathbf{5 3 6}}
$$

\section{Sampling procedure}


A two-stage sampling technique was used to select the study subjects. Four sub-cities were randomly selected using a simple random sampling method from 8 sub-cities. The total population in 4 selected sub-cities: Buchanan, Arada, Alelu, and Awasho were 36877, 34529, 31734, and 36370 respectively (139510) of which 6697 was children 6-23 months of age. The calculated sample 536 was allocated equally among the selected 4 sub-city i.e. 134 mothers having children 6- 23 months. To get the individual sample units or subjects at the household level a documented list of all target groups of the sub-city was used from the health post to acquire a list of the target group.

The first individual was identified by lottery method and every $\mathrm{K}^{\text {th }}$ mother with eligible children were picked from 4 sub-city using systematic random sampling thus a child was selected in each sub-city and his/her mother was interviewed accordingly. From each household, one eligible child with mother at the time of the survey was selected, incase $>2$ eligible children found the younger was taken and the process had been continuing until next $\mathrm{K}^{\text {th }}$ in the same direction. If the mother was absent on the date of data collection she was substituted by the next mother from the same sub- city after one revisit was made.

\section{Data collection procedures}

Six diploma holder data collectors and two BSc. holder supervisors were participated to collect the data from mothers who had children aged 6-23 months by using a face-to-face interview during a home-tohome visit with semi structured questionnaire. The questionnaire comprised of data on background characteristics of mother and youngsters, maternal health practice, and child feeding practices. For data quality control, the questionnaire was first developed in English and translated to the local language, Afan Oromo, and then back-translated to English by two people, who have good command in both languages for consistency. The training was given to data collectors and supervisors for 2 days and the questionnaire was pre-tested in $5 \%$ of mothers, in the study area, which is not included in the actual study to assess the content and approach of the questionnaire and a necessary correction was made. All questionnaires were checked daily for completeness accuracy and cleaned before analysis.

\section{Operational definitions}

Timely introduction of CF: The proportion of children 6-23 months that were introduced to solid and semisolid foods at 6 months of age $[5,6]$.

Minimum dietary diversity is that the proportion of youngsters 6-23 months aged who receive foods from 4 or more food groups with the food groups consisting; (I) grains, roots, and tubers; (II) legumes and nuts; (III) dairy products; (IV) flesh foods; (V) eggs; (VI) vitamin A-rich fruits and vegetables; and (vii) other fruits and vegetables the prior day of the study $[5,6]$.

Minimum meal frequency is that the proportion of breastfed and non-breastfed children 6-23 months aged, who receive solid, semi-solid, or soft foods (but also including milk feeds for non- breastfed children) the minimum number of times or more during the previous day. The minimum is defined as 2 
times for breastfed infants 6-8 months, 3 times for breastfed children 9-23 months, 4 times for nonbreastfed children 6-23 months $[5,6]$.

A minimum acceptable diet is the proportion of children 6-23 months of age who receive both minimum meal frequency and minimum dietary diversity during the previous day of study. ACFP: - defined appropriate when they meet all the four indicators timely introduction, minimum meal frequency, and minimum dietary diversity and MAD while it is considered inappropriate when it fails to fulfill even a single indicator $[5,6]$.

Knowledge and attitude about ACFP were measured among respondents using 10 items [(1). ever breastfeed your child? (2). Time of initiation of first breast milk? (3) How long you gave Breast Milk to the baby? (4) Having information on CF; (5). Know the advantage of iron-rich food? (6). know the benefit of lodized salt? (7). Frequency of feeding solid, semisolid, or soft food (8) sources information about the advantage of breast feeding? (9). sources information about commercially prepared complementary food (10). How to prepare complementary foods] And 4 items [ 1 it is important to help my child when she eats, 2. It is important to feed my child to eat slowly and patiently, 3. It is important to encourage my child to eat and 4.1 talk to my child during feeding by looking straight in the eyes] respectively. Therefore, mothers responded "Yes" was given a value of "1," while those said "No" were given "0" and summed up.

Those mothers scored mean or more were considered as having knowledgeable, whereas those scored below mean value was characterized as not knowledgeable similarly procedure was followed for attitude those who scored mean or more value were considered as having a good attitude, whereas those scored below mean value were categorized as poor attitude on ACFP.

\section{Inclusion and exclusion criteria}

All mother-child pairs age 6-23 months living in Shashamene city were taken as source population. Whereas mothers - child pairs aged 6-23 months living in the selected household during the study period and lived in the study area for $\geq 6$ months as well presented during the study period were included as study population while those resided in the study area for $<6$ months were excluded from the study subjects.

\section{Variables}

\section{Independent and dependent variables}

The outcome variable for this study was the magnitude of knowledge, attitude, and practices (KAP) regarding $\mathrm{CF}$ and its components. The independent variables were maternal, child, and household characteristics. Briefly, the description of the variables was as follows: Socio- demographic characteristics (age, sex, type of family size, monthly income), Partner education level, household wealth index, food insecurity, occupation, residence, knowledge, and attitude of mothers, Obstetric history :( Pregnancy History, ANC, PNC, delivery mode and Place of delivery, birth space and no of Parity) were the independent variables. 


\section{Statistical analysis}

Data were coded and entered into Epi-info 3.5.1 statistical software and analysis was made by using statistical package for social science (SPSS) version 25. Descriptive statistics such as frequencies, proportions, means, and standard deviation are used to describe data. Bivariate analysis was made to see the relation of each independent variable with the dependent variable. Finally, independent variables associated during bivariate analysis with P-value $<0.25$ were entered into multivariable logistic regression analysis used to determine the strength of association between independent and dependent variables. Odds ratios along with $95 \% \mathrm{Cl}$ were reported and the statistical significance was declared at the $\mathrm{p}$-value < 0.05. A multivariate Logistic regression model was used to control confounders.

\section{Study Result}

\section{Socio-demographic Characteristics of Study Subjects.}

The study included 520 mother-child pairs with a perfect response rate of $100 \%$. Mothers' mean age was $24.81 \mathrm{SD}(+0.87)$ years. More than half of the study participants were between the ages of 25 and 34 . $14.8 \%$ of households do not have a job. 481 (92.5\%) of the total study subjects were married, and 325 $(62.5 \%)$ were Muslim. More than half of the respondents 333 (64\%) belonged to the Oromo ethnic group, $89(17.1 \%)$ is Amahara, and the rest is wolayita, Tigre, and other, accounting for $47(9 \%), 11(2.1 \%)$, and $40(7.6 \%)$ respectively. Three hundred twenty-seven (62.9\%) of the households have a family size of 4-6 members, 101(19.4) have 1-3 household members, and the rest have more than seven family members (table1).

Table 1: Socio-demographic characteristics of respondents in Shashemene, Oromia- Ethiopia, 2020. $(\mathrm{N}=520)$ 


\begin{tabular}{|c|c|c|}
\hline Characteristics & Frequency & Percent \\
\hline \multicolumn{3}{|c|}{ Age of mothers/caretakers } \\
\hline$<=24$ years & 151 & 29.0 \\
\hline $25-29$ years & 231 & 44.4 \\
\hline $30-34$ years & 100 & 19.2 \\
\hline$>=35$ years & 38 & 7.3 \\
\hline \multicolumn{3}{|c|}{ Educational status of mother/caretaker } \\
\hline Basic education & 117 & 22.5 \\
\hline primary education & 236 & 45.4 \\
\hline secondary education & 113 & 21.7 \\
\hline higher education & 54 & 10.4 \\
\hline \multicolumn{3}{|c|}{ Mothers/caretakers occupation } \\
\hline House wife & 244 & 46.9 \\
\hline House worker & 147 & 28.3 \\
\hline Government employee & 64 & 12.3 \\
\hline Student & 18 & 3.5 \\
\hline Merchant & 44 & 8.5 \\
\hline Daily laborer \&other & 2 & 0.57 \\
\hline \multicolumn{3}{|c|}{ Educational status of husband } \\
\hline Basic education & 71 & 13.7 \\
\hline primary education & 189 & 36.3 \\
\hline secondary education & 192 & 36.9 \\
\hline higher education & 68 & 13.1 \\
\hline \multicolumn{3}{|l|}{ Husband's occupation } \\
\hline Gov. worker & 149 & 28.7 \\
\hline Farmer & 77 & 14.8 \\
\hline Marchant & 217 & 41.7 \\
\hline Daily laborer \&other & 77 & 14.8 \\
\hline Family income per mor & & \\
\hline
\end{tabular}




\begin{tabular}{|lll|}
$<=999$ & 13 & 2.5 \\
$1000-1999$ & 84 & 16.2 \\
$2000-2999$ & 129 & 24.8 \\
$3000-3999$ & 89 & 17.1 \\
$>=4000$ & 205 & 39.4 \\
\hline
\end{tabular}

\section{Mothers' Knowledge on Infant and Young Child Feeding practices}

In terms of mothers' knowledge about child feeding, the average of knowledge questions with yes answers is calculated, and participants who scored higher than the mean, 3.91, were considered knowledgeable and vice versa. Among the 520 study participants interviewed, 465(89.4\%) heard information about BF. 496 (95.4\%) of the mothers began breastfeeding within one hour of giving birth. The majority of the mothers $353(67.9 \%)$ were aware that complementary foods should be introduced to their children at the age of six months. At the age of 6 months, approximately $353(67.9 \%)$ mothers initiated CF and the majority of mothers 398 (76.5\%) prefer homemade CF (Table 2).

Table 2: Knowledge of mothers on infant and young child feeding among children aged 6-23 Months in Shashemene city, Oromia- Ethiopia, $2020(n=520)$ 
Variable

Frequency

percent

Proportion of participants initiation of breast feeding after birth

After 1 hour

24

4.6

Immediately after birth within one hour

496

95.4

Participants Knowledge on Time of initiation of CF

At greater and Less than 6 month

167

32.1

At 6 month

353

67.9

Participants Sources of information about Advantage of Breast Milk

Family and others

55

10.6

Media

465

89.4

Bottle feeding with a nipple yesterday during the day or night after birth?

Yes

448

86.2

No

72

Knowledge about advantage of iodized salt

Yes

365

70.2

No

155

28.8

Knowledge about advantage of Iron

Yes

267

51.3

No

253

48.7

Mothers Breast feeding status of the child

Stop at 6 months Yes

31

6

No

489

94

Continued breastfeeding at 1 year

Yes

133

89.9

No

15

10.1

Continued breast feeding at 2year $(n=87)$

Yes

81

93.1

No

6

6.9

Exclusive breastfeeding under 6 months 


\begin{tabular}{|lcc|}
\hline \multicolumn{1}{|c|}{ Yes } & 489 & 94 \\
\hline No & 31 & 6 \\
\hline Introduction of solid, semi-solid or soft foods among children age & $6-8$ month. & \\
\hline Frequency less than 4 times & 88 & 94.6 \\
\hline Frequency greater than or equals 4 times & 5 & 5.3 \\
\hline Introduction of solid, semi-solid or soft foods among children age 9-23 month & \\
\hline Frequency less 4 times & 408 & 95.5 \\
\hline Frequency greater than or equals 4 times & 19 & 4.4 \\
\hline
\end{tabular}

\section{Mother's Attitudes about Infant and Young Child Feeding practices}

The average score for positive attitude about ACFP was 74\%. The documented mother's attitude toward feeding during illness revealed that $187(36 \%)$ of the mothers reported that the quantity and frequency of feeding should be reduced during child illnesses, $147(28.3 \%)$ withheld the quantity and frequency, 123 $(23.7 \%)$ maintained the same quantity and amount, and only $63(12.1 \%)$ reported increasing the quantity and frequency.

This study's findings also revealed the mothers' beliefs about cultural and social food taboos investigated, with 44 (8.4\%) mothers believing in food taboos related to childhood illnesses. If the child is sick, they avoid foods like cabbage meat and milk. Mothers' food preferences and preparation were also recorded; 398 (76.5\%) and 122 (23.5\%) preferred homemade and commercially available complementary foods to feed their children, respectively. 452 (86.9\%) mothers preferred to prepare separate complementary food, while $68(13.1 \%)$ mothers preferred to prepare child food with adult food. This table also demonstrates the dominance of cow's milk 339 (65.2\%) as a major food item to complementary food followed by Vegetable 77 (14.8\%) (Table3).

Table 3: Frequency of respondent's Attitude on IYCF practice among children aged 6-23 months old in Shashemene city, Ethiopia, 2020 


\begin{tabular}{|c|c|c|}
\hline Attitude & No & $\%$ \\
\hline \multicolumn{3}{|l|}{ CF practices and frequency during illness } \\
\hline Decrease quantity and frequency of food during illness & 187 & 36.0 \\
\hline Withheld quantity and frequency of food during illness & 147 & 28.3 \\
\hline Maintain same quantity and frequency during illness & 123 & 23.7 \\
\hline Increase food quantity and frequency during illness & 63 & 12.1 \\
\hline \multicolumn{3}{|l|}{ Cultural and social food taboos during illness } \\
\hline Cabbage & 35 & 79.5 \\
\hline Meat\& cabbage & 8 & 18.18 \\
\hline Milk & 1 & 2.27 \\
\hline \multicolumn{3}{|l|}{ Preferences about complementary foods } \\
\hline Home- made & 398 & 76.5 \\
\hline Commercially available foods & 122 & 23.5 \\
\hline \multicolumn{3}{|l|}{ Mothers preference about preparation of complementary foods } \\
\hline Prepare separately CF for children & 452 & 86.9 \\
\hline Prepare combine as an adult food & 68 & 13.1 \\
\hline \multicolumn{3}{|l|}{ Preferred food in CF } \\
\hline Bread & 65 & 12.5 \\
\hline Vegetable & 77 & 14.8 \\
\hline Cow milk & 339 & 65.2 \\
\hline Fruits/juices & 39 & 7.5 \\
\hline Met Dietary diversity for both breast and non-breast food children & 291 & 56 \\
\hline
\end{tabular}

Regarding the practice of mothers about infant and young child feeding practice; Interestingly, there are encouraging practices detected in this study almost all mother $519(99.8 \%)$ breast feed their children after delivery, 496/520(95.5\%) initiated Breast feed earlier, and most of them 482(92.7\%) feed breast milk based on child demand, whereas $489(94 \%)$ fed EBF vs. 58\% of the national fig. of 2016 EDHS [11]. It is recommended that a child continues to breastfeed until age of 2year. However, in Ethiopia, the percentage of children who are currently BF decreases from $91 \%$ among children age 12-17 months to $76 \%$ among children age 18-23 months as of EDHS 2016 that is a bit comparable with this finding. 
In contrary, the discouraging practices were 31 (6\%) mothers start CF earlier, breast fed continuation was not as recommended at $1 \& 2$ years / I.e. not satisfactory but by far better than that of Kosovo [12]. The other discouraging practice was bottle with nipple feeding which accounts for about $86 \%$. Over all, the mothers' good knowledge and positive attitude about appropriate IYCF practice were $319(61.3 \%)$ and $313(74 \%)$ among 6-23moths age old children in the study area.

\section{Bivariate and Multivariable Analyses}

Factors related to mother's knowledge of infant feeding of children aged 6-23 months were identified: A Variables with P.Values less than 0.25 in bivariate analyses were re-entered into a multivariate logistic regression to account for potential confounders. There was no correlation between maternal age, family size, household income and knowledge of mother on infant feeding in this study.

Knowledge of mothers with higher levels of education was reported higher on infant and young child feeding compared with those mothers who had completed secondary education or no schooling (AOR= 2.26(1.08-4.71)).* After adjusting for maternal education and other potential confounders, 'working mother' (mothers 'occupation) regardless of type of occupation remained as a significant association factor for IYCF practices compared with Homemaker. The odd of being Knowledge able about IYCF practices among mothers who had occupation (AOR: 2.94, 95\%, Cl, (1.53-5.64)) *** were higher than that of mothers who did not had occupation (Table 4).

Table 4: Factors associated with Knowledge of mother on infant feeding of children age 6-23 months, Shashamene, Oromia-Ethiopia, 2020 
Variable

Knowledge of mother on infant and young child feeding

Has no

Knowledge

№ $(\%)$

Has

Knowledge

$\operatorname{COR}(95 \% \mathrm{Cl}$

№ $(\%)$

\section{Age of mothers/caretakers}

$<=24$ years

140(92.7)

$11(7.3)$

$2.38(0.82,6.93)$

1

25-29 years

16(6.9)

215(93.1)

$2.52(0.91,6.91)$

$2.67(.90,7.87)$

$30-34$ years

$6(6.0)$

94(94.0)

$2.93(0.88,9.75)$

32(84.9)

1

2.72(.98, 7.57)

$>=35$ years

6(15.8)

Educational status of mother/caretaker

\begin{tabular}{lll} 
Basic education & $10(8.5)$ & $107(91.5)$ \\
\hline primary education & $18(7.6)$ & $218(92.4)$ \\
$\begin{array}{l}\text { secondary } \\
\text { education }\end{array}$ & $10(8.8)$ & $103(91.2)$ \\
higher education & $1(1.9)$ & $53(98.1)$
\end{tabular}

$2.2(1.10-4.69)$ * $\quad 2.26(1.08-4.71)$ *

\section{Mothers/caretakers occupation}

Homemaker

113(46.3)

131(53.7)

139(65.6)

1

1

Unskilled worker

73(34.4)

(139(65.6)

49(76.6)

0.96(0.06- 1.51)

$0.28(0.03,2.51)$

1.42(0.83-2.43)

$0.29(.036,2.45)$

1

$1.73(1.19-$
$2.52) * * *$

$2.52)^{\star \star *}$

$3.27(1.83-5.83)$ *

skilled worker

\begin{tabular}{|c|c|c|}
\hline$<=999$ & $1(7.7)$ & $12(92.3)$ \\
\hline
\end{tabular}

2.94(1.53-

$5.64)^{\star * \star}$

$0.78(.25-2.42)$

\begin{tabular}{|lllll|}
\hline $1000-1999$ & $10(11.9)$ & $74(88.1)$ & $0.54(0.23$, & $0.83(0.10,6.92)$ \\
\hline $2000-2999$ & $6(4.7)$ & $123(95.3)$ & $1.50(0.56,4.01)$ & $0.53(0.22,1.27)$ \\
\hline $3000-3999$ & $8(9.0)$ & $81(91.0)$ & $0.74(0.30,1.83)$ & $1.47(0.55,3.95)$ \\
\hline$>=4000$ & $14(6.8)$ & $191(93.2)$ & 1 & 1
\end{tabular}




\section{Family size}

\begin{tabular}{|lllll|}
\hline $1-3$ & $5(5)$ & $96(95)$ & $1.10(0.30,3.94)$ & $1.29(.82-2.05)$ \\
\hline $4-6$ & $29(8.9)$ & $298(91.1)$ & $0.59(0.22,1.57)$ & $1.16(0.32,4.20)$ \\
\hline$>=7$ & $5(5.4)$ & $87(94.6)$ & 1 & 1 \\
\hline
\end{tabular}

Abbreviations: Cl-confidence interval, COR-Crude odd ration, AOR-Adjusted odd ratio,

P. vale $\leq 0.05^{\star}$, P. value $<.001 \star \star \star$

The findings revealed that, of the total entered variables, Bottle feeding, Initiation of CF at 6 months, and $T V$, radio, reading, and health professionals are all good places to get information about the benefits of breast milk. Minimal dietary diversity was attained.

Maternal knowledge about IYCF practices was One of the predictor variables that statistically significant. The odd of Introduction of solid, semi-solid or soft foods for children from knowledgeable mothers was 4.31 times higher when compared with children of mothers with no knowledge (AOR: 4.3195\%,Cl:(2.92$6.36))^{\star \star \star}$

Knowledge of iron-rich foods and Knowledge of iodine-rich foods are factors significantly associated with Knowledge of mother on appropriate infant feeding, whereas the rest variables were not associated after controlling for potential confounders, despite being associated in bivariate analyses. Approximately $73 \%$ of bottle-feeding mothers were unaware of proper infant feeding ( $A O R=0.27,95 \% \mathrm{Cl}:(0.13,0.55)$ ). The start of CF at 6 months was found to be statistically significantly related to the mother's knowledge of appropriate infant feeding. Mothers who began CF at 6 months were approximately six times more likely to be knowledgeable about appropriate infant feeding ( $A O R=6.21,95 \% \mathrm{Cl}:(2.97,13.0)$ ).

Sources of information about the benefits of breast milk and mothers who met the minimum dietary diversity had four and two times more knowledge on appropriate infant feeding practice, respectively $(A O R=4.34,95 \%(1.96,9.60)),(A O R=2.21,95 \% \mathrm{Cl},(1.01,4.85))$. After controlling for potential confounders, our findings showed that mothers who did not know about proper infant feeding were $97.1 \%$ and $97.8 \%$ less likely to give iron and iodine-rich food, respectively ( $A O R=0.029,95 \% \mathrm{Cl},(0.04,0.21), A O R=0.022,95 \%$ $\mathrm{Cl},(0.03,0.16)$ (Table 5).

Table 5: Factors associated with Knowledge of mother on infant and young child feeding of children age 6- 23 months, Shashamene, Southern Ethiopia, 2020 


\section{Knowledge of mother on appropriate infant feeding}

\begin{tabular}{|c|c|c|c|c|}
\hline \multirow{3}{*}{ Variables } & Has no & Has & \multirow{3}{*}{$\operatorname{COR}(95 \% \mathrm{Cl}$} & \multirow{3}{*}{ AOR $(95 \% \mathrm{Cl})$} \\
\hline & Knowledge & Knowledge & & \\
\hline & No (\%) & No (\%) & & \\
\hline \multicolumn{5}{|c|}{ Bottle feeding } \\
\hline Yes & $25(5.6)$ & 423(94.4) & $0.24(0.12,0.49)^{\star}$ & $0.27(0.13,0.55)^{*}$ \\
\hline No & 14(19.4) & $58(80.6)$ & 1 & 1 \\
\hline \multicolumn{5}{|c|}{ Minimum meal frequency } \\
\hline Yes & $18(5.5)$ & $309(94.5)$ & $0.47(0.24,0.92)^{\star}$ & $0.55(0.28,1.08)$ \\
\hline No & 21(10.9) & 172(89.1) & 1 & 1 \\
\hline
\end{tabular}

Introduction of solid, semi-solid or soft foods

$\begin{array}{llllc}\text { Received } & 82(40) & 324(100) & 4.56(3.12-6.67) & 4.31(2.92-6.36)^{\star \star \star} \\ \text { Not received } & 119(59.2) & 77(24.1) & 1 & 1\end{array}$

Immediate initiation of breast feeding after birth

\begin{tabular}{lcccc} 
within one hour (Yes) & $36(7.3)$ & $460(92.7)$ & $1.82(0.52,6.41)$ & $0.60(0.16,2.13)$ \\
\hline greater than 1 hour(no) & $3(12.5)$ & $21(87.5)$ & 1 & 1 \\
\hline $\begin{array}{l}\text { Exclusive Breast feeding } \\
\text { Yes }\end{array}$ & $38(7.7)$ & $453(92.3)$ & $2.66(1.25,5.65)$ & $2.66(0.34,20.5)$ \\
\hline No & $1(3.4)$ & $28(96.6)$ & 1 & 1 \\
\hline Initiation of CF & & & & \\
\hline at 6 month & $11(3.1)$ & $342(96.9)$ & $0.16(.07,0.33)^{*}$ & $6.21(2.97,13.0)^{*}$ \\
At less than and greater than & $28(16.8)$ & $139(83.2)$ & 1 & 1 \\
6 month & & & &
\end{tabular}

Sources of information about Advantage of Breast Milk

\begin{tabular}{|lllcc|}
\hline Family and others & $12(21.8)$ & $43(78.2)$ & 1 & 1 \\
\hline $\begin{array}{l}\text { TV, Radio, Reading and } \\
\text { health professionals }\end{array}$ & $27(5.8)$ & $438(94.2)$ & $3.23(1.43-5.67) *$ & $4.34(1.96,9.60) *$ \\
\hline
\end{tabular}

Minimum

dietary diversity

Met Minimum

$10(4.5)$

$211(95.5) \quad 0.44(0.21,0.92) *$

$2.21(1.01,4.85)$ * 


\begin{tabular}{|c|c|c|c|c|}
\hline Not Met Minimum & 29(9.7) & $270(90.3)$ & 1 & 1 \\
\hline \multicolumn{5}{|c|}{ Knowledge about iron rich food } \\
\hline Yes & $1(0.4)$ & 266(99.6) & 1 & 1 \\
\hline no & $38(15)$ & 215(85) & $0.021(0.03,0.15)$ & $0.029(0.04,0.21)$ * \\
\hline \multicolumn{5}{|c|}{ Knowledge about iodine rich food } \\
\hline Yes & $14(3.8)$ & $351(96.2)$ & 1 & 1 \\
\hline No & 25(16.1) & $130(85.9)$ & $0.20(0.10, .0 .41)^{\star}$ & $0.02(0.03,0.16)^{\star}$ \\
\hline \multicolumn{5}{|l|}{ Mothers attitude } \\
\hline Positive & $108(69.2)$ & 283(77.7) & $1.55(1.02-2.36)^{\star}$ & $1.80\left(1.15-2.82^{\star}\right.$ \\
\hline Negative & 48(30.8) & $81(22.3)$ & 1 & 1 \\
\hline
\end{tabular}

P. value $=\leq 0.05^{\star}$, P. value $<.001 * * *$

\section{Discussion}

For proper growth and development of infant Optimum nutrition is essential. Thus, in this study the knowledge, attitudes and practice of mothers toward ACFPs among mothers of infants and young aged children 6-23 months were assessed and revealed $61.3 \%, 74.3 \%$ and $32 \%$ respectively. The present study shown that, 353(67.9\%) of mothers were introduced CF at correct age /time (i.e. 6 months) of the child birth this opposed the studies done in south Africa $44.1 \%$ and Ugand $27 \%$ that showed complementary feeding began within 2-3 months [13].

This might be due to difference in time, socio culture version. In current study a large majority 496 (94.6\%) of mothers knew and imitate breast milk within one hour of delivery as recommended by WHO this is in fact very good practices that is helpful for successful lactation and weaning practices. Breast feeding was continued till 1 and 2 years by $89.9 \%$ and $93.1 \%$ of mothers respectively this is encourage able practice which was supported by study done in Karachi Hospital [14] in which the initiation of breastfeeding soon after birth was very common.

Bottle feeding, start of CF, Sources of information on the Benefits of Breast Milk, mother Knowledge of iron-rich foods and mother knowledge of iodine-rich foods were significant factors associated with mother knowledge of infant feeding among children aged 6-23 months. Children from low-income families were also found to be at a significantly higher risk of receiving inappropriate CF.

The study's findings revealed that mothers who knew about infant feeding had practice $73 \%$ (AOR: 0.27 $95 \% \mathrm{Cl}(0.13,0.55)$ less bottle-feeding than those who did not. This finding is supported by a study 
conducted in Adudabi, which found that mothers with less knowledge about infant feeding practice formula feed before 6 months, complaining of decreased milk production and the baby appearing hungry or unsatisfied after feeding [15].

Bottle feeding with a nipple the day preceding the survey that was during the day or night after birth nearly account for $86 \%$ in this study area which was discouraging practice. This is supported by another study conducted in Jigjiga with the highest percentage of mothers $(90.9 \%)$ thought as bottle feeding was a better option for feeding non-breastfed children and for medical problems [16].

This suggests that mothers who are unfamiliar with appropriate infant feeding prefer bottle-feeding to breastfeeding for a variety of reasons, including even who received advice from a healthcare provider about the importance of breastfeeding during antenatal and postnatal visits, having been counseled about the appropriate breast feeding Practice at any time, and having previous breast feeding practices experience. At six months, mothers who know infant feeding initiate CF 6.2 times more than mothers who do not know infant feeding (AOR:6.21 $95 \% \mathrm{Cl}$ : $(2.97,13.0)$ ). This finding is similar to a study done in India by which found that $52 \%$ of children started complementary food at the age of 6 months, and another study done in Jigjiga, Ethiopia, which found that $90 \%$ of children's mothers started CF at 6 months, but only $27.3 \%$ of the mothers were aware that adding ghee or oil enriches children's diet $[8,16]$.

These similarities may be explained by the fact that these two regions have similar cultures and receive health education on exclusive breastfeeding and appropriate CF from health extension workers. Sources of information such as mass media (TV, Radio) and health professionals are four times more significant (AOR: $4.3495 \% \mathrm{Cl}(1.96,9.60)$ ) for mother's knowledge on infant feeding about the benefits of breast milk. This discovery is the result of a well-supported study conducted in Bahir Dar [17].Reported Mothers who had access to a radio were 1.7 times more likely to have adequate knowledge than their counterparts who did not have access to a radio. In contrast to the previous study, conducted in India [8] found that the primary source of knowledge about complementary food items was family (52\%), followed by healthcare professionals, electronic media, and relatives. This disparity could be attributed to differences in socioeconomic, cultural, and technological access in each country.

Mothers' knowledge of dietary diversity and child feeding was significantly associated with their child's infant feeding practice (AOR: $2.2195 \% \mathrm{Cl}(1.01,4.85))$. Furthermore, this study confirmed that mothers' knowledge of dietary diversity and child feeding practices influence appropriate dietary diversity feeding practice. Mothers who knew a lot about dietary diversity and child feeding practices were more likely to feed their children a variety of foods than their counterparts. This finding is consistent with the findings of a study conducted in Addis Ababa, Ethiopia [18]. And a study in Adea woreda found that mothers who were not knowledgeable about dietary diversity were $70 \%$ less likely to practice good dietary diversity for their 6-23-month-old children than their counterparts $[18,19]$.

This demonstrates a better understanding of the various food items and their benefits, which assists the mother in implementing appropriate child feeding practices. Mothers who were unaware of the benefits of iron-rich foods were $97 \%$ less effective in infant feeding practice than mothers who were aware of the 
benefits of iron-rich foods (AOR: 022,95 \% Cl) $(0.03,0.16)$ ). Furthermore, a study conducted in Bahir Dar revealed that mothers' knowledge of Infant young CF practice, particularly on the frequency and type of complementary food, the need for iron-rich foods, and additional foods during illness, was very low [17]. This could imply that mothers who have access to micronutrients are less likely to practices CF.

Other independent predictors were maternal education and mothers' occupation that showed a stronger association with child feeding practices. In short the higher the level of maternal education the better the IYCF practice. This supported by previous evidence from study done in Sri lank that shown maternal education and mothers' occupation were a strong predictor of child Nutrition $[20,21]$.This is possibly due to that educated, and employed mothers have high chance of having information on child care as well they get better access to improved health services and economy. This implies women education and empowering have great role in improving IYCF practices.

\section{Conclusion And Recommendation}

The findings evaluated among mothers with children under the age of two years show that mothers have significant and appropriate knowledge, attitude, and practice regarding early initiation of breastfeeding, exclusive breastfeeding, initiation of appropriate complementary feeding, as well as the preference for preparing home-based complementary feeding that focuses on MDD and MAD. Besides, the study reveals that mothers' knowledge and attitude about IYCF feeding during illnesses were the very is limited. The practices and attitude of mothers' about Bottle feeding was high though it was discouraging practice / feeding which was the primary cause of child under/malnutrition. Bottle feeding, sources of information about the benefits of breast milk, a minimum of dietary diversity and, MAD, knowledge about iron-rich foods, and knowledge about iodine-rich foods were the independent factors that were significantly associated with mother knowledge about appropriate infant feeding practices.

\section{Recommendation}

It was stated in previous studies as $2 / 3$ of child death was attributed to inappropriate complementary feeding, in this study knowledge was low. So, to scale up these successful interventions to levels that would make an impact. Health Bureau, NGOs and other development sectors should give special attention to:

- Educational/ counseling intervention on benefits of breast feeding, CF, and dietary diversity for mothers and /or caregivers are essential for improving IYCF practices, particularly for mothers with younger children about, time, variety, quantity and frequency of food and discourage bottle-feeding practices to reduce malnutrition

- HCWs should encourage the women to attend more ANC as well as give attention to mothers during counseling on Infant and young child feeding practices / nutrition /educational interventions to improve complementary feeding practices and brings positive attitude about IYCF practices

- To come up with the real figure large scale follow-up study will be proposed for the researcher 


\section{Acronyms /abbreviations}

\begin{tabular}{ll} 
ACFP: & Appropriate complementary feeding practice \\
\hline ANC: & Antenatal care \\
\hline AOR: & Adjusted odds ratio \\
\hline CF: & Complementary Feeding \\
\hline Cl: & Confidence Interval \\
\hline COR: & Crude odds ratio \\
\hline CSA: & Central Statistical Agencies \\
\hline C/S & Caesarian section \\
\hline EDHS: & Ethiopian Demographic and Health Survey \\
\hline HCWs & Health Care workers \\
\hline PNC: & Post-natal care \\
\hline IYCF: & Infant and young child feeding \\
\hline MDD: & Minimum dietary diversity \\
\hline MAD: & Minimum acceptable diet \\
\hline MMF: & Minimum meal frequency \\
\hline SDGs: & Sustainable Development Goals \\
\hline SPSS: & Statistical Package for the Social Sciences software \\
\hline TBAs & Traditional birth attendants \\
\hline UNICEF: & United Nation Children's Funds \\
\hline WHO: & World Health Organization \\
\hline
\end{tabular}

\section{Declarations}

\section{Acknowledgments}

The investigators would like to thank Madda Walabu University, Shashemene Campus for providing support to conduct this research. The investigators express their heartfelt gratitude to individuals and organizations (Shashemene Health Bureau, Shashemene City Administration) for providing necessary information that helps to conduct this research. Lastly, we would like to extend our appreciations to data 
collectors and study participants for the support they provided us throughout the whole process of the data collection period.

Funding: The authors stated No specific funding for this work.

Availability of data and material: Data are available without restriction in the body of manuscript.

\section{Authors' contribution}

$\mathrm{JA}$ and $\mathrm{KK}$ were involved in proposal writing, designed the study, and participated in coordination; supervision and the overall implementation of the project analyzed the data and finalized the manuscript. $\mathrm{KH}$ conceived the study and participated in all stages of the study and revision of the manuscript. All authors read and approved the final manuscript.

\section{Ethical approval and consent for participants:}

This study was conducted according to the guidelines laid down in the Declaration of Helsinki and all procedures involving research study participants were approved by the Madda Walabu University, the ethics committee. An informed consent form was made available to the study participants then the consent was obtained from all subjects/participants. Verbal consent was witnessed and formally recorded as well permission was obtained from relevant authorities. Finally, information regarding the importance of ACFP and nutritional advice were given to the respondents by interviewers during data collection. Beside this, intervention strategies would be developed to take appropriate action to improve IYCF.

\section{Consent sent for publication}

Not applicable

\section{Competing interest}

The authors declare that there is no conflict of interests regarding the publication of this paper.

\section{Author's details}

${ }^{1}$ Department of Public Health, School of Health Science, Madda Walabu University Shashemene Campus, Shashemene, Oromia, Ethiopia.

${ }^{2}$ Department of Nursing, School of Health Science, Madda Walabu University Shashemene Campus, Shashemene, Oromia,Ethiopia

\section{References}

1. Yalew BM. Prevalence of malnutrition \& associated factors among children age 6-59 months at Lalibela town, north Wollo Zone, north Ethiopia. J. Nutr Disorders, 2014. 
2. Semahegn A, Tesfaye G, Bogale A. CF practice of mothers and associated factors in Hiwot Fana specialized hospital, eastern Ethiopia. Pan Afr Med J, 2014; 18:143

3. Guiding principles for CF of the breastfed child. Division of health promotion and protection. In Program FaN, editor. Pan American health organization/WHO. Washington/Geneva: PAHO, WHO, 2003.

4. Manchuria CW, Kogi-Makau W, Muroki NM. Dietary intake, feeding, \& care practices at children in kathonzweni, division, Makuenl, district, Kenya. East Afr Med J.,2004

5. WHO. Indicators for assessing IYCFP. Part 1: Definition. Geneva: WHO, 2008

6. WHO. Indicators for assessing IYCFP. Part II\&III: Definition. Geneva: WHO, 2010

7. Disha A, Rawat R, Subandoro A, Menon P. IYCF practices in Ethiopia and Zambia and their association with child nutrition: analysis of demographic and health survey data. Afr J Food Agric Nutr Dev.,2012

8. Ramesh Chand1, Ashok Kumar1, Nutan Singh1, Soniya Vishwakarma, Knowledge, attitude and practices about CF among mothers of children aged 6 to 24 months in a tertiary care center of Kumaun region, India. Int J Contemp Pediatr, 2018.

9. Tigist Kassa, Berhan Meshesha, Yusuf Haji, and Jemal Ebrahim. Appropriate CF practices and associated factors among mothers of children age 6-23 months in southern Ethiopia, 2016 Pediatrics, 16:131 DOI 10.1186

10. Abate Area, Dereje Yohannes, and Mulugeta Yohannis. Determinants of ACFP among mothers having children 6-23 months of age in rural Damot sore district, Southern Ethiopia; BMC Nutrition,2017; 3:82 DOI 10.1186

11. EDHS, 2015. Addis Ababa and Calverton: CSA and ORC Macro; 2016

12. Merita Berisha, Naser Ramadani, Rina Hoxha, Sanije Gashi, Valbona Zhjeqi, Drita Zajmi, IlirBegolli: Knowledge, Attitudes, and Practices of Mothers in Kosova about CF for Infant and children 6-24 Months, 2017

13. Ajani SR. Assessment of dietary diversity in 6 Nigerian states.Afr JBiomed Res.,2010; 13: 161-7

14. Shazia Samad Mohsin, Abdul Sattar Shaikh, Rehana Shaikh, Nighat Haider4 and Arit Parkash:Knowledge Attitude and Practices of Mothers regarding CF; Journal of the Dow University of Health Sciences Karachi , 2014, Vol. 8 (1): 21-25

15. Mai Isam Al Ketbi1, Sultan Al Noman1, Abdelqadir Al Ali1, Ebtihal Darwish, Maha Al Fahim and Jaishen Rajah, Knowledge, attitudes, and practices of breastfeeding among women visiting Primary healthcare clinics on the island of Adudabi, 2018

16. Yimer Mihretie. Maternal Knowledge on CF Practice and Nutritional Status of Children 6-23 month in Jigjiga Town. Glob J Nutri Food Sci. 1(1), 2018

17. Yeshalem Mulugeta Demilew. Factors associated with mothers' knowledge of infant \& Young child feeding recommendations in slum areas of Bahir Dar City, Ethiopia, 2017 
18. Dagmawit Solomon, Zewdie Aderaw \& Teketo Kassaw Tegegne, Minimum dietary diversity and associated factors among children aged 6-23 months in Addis Ababa, Ethiopia, 2017

19. Andualem Agize, Dube Jara, \& Getiye Dejen, Level of Knowledge and Practice of Mothers on Minimum Dietary Diversity Practices \& Associated Factors for 6-23-Month-Old Children in Adea Woreda, Oromia, Ethiopia, 2017.

20. Upul Senarath, Sanjeeva S. P. Godakandage, Hiranya Jayawickrama, Indika Siriwardena and Michael J. Dibley. Determinants of inappropriate complementary feeding practices in young children in Sri Lanka: secondary data analysis of Demographic and Health Survey 2006-2007, maternal and child nutrition. DOI: 10.1111/j.1740-8709.2011.00375.

21. Mya KS, Kyaw AT, Tun T (2019) Feeding practices and nutritional status of children age 6-23 months in Myanmar: A secondary analysis of the 2015-16 Demographic and Health Survey. PLoS ONE 14(1): e0209044. https://doi.org/10.1371/ journal.pone.0209044 